\title{
Short-term Impacts of COVID-19 on the Malawian Economy: Initial Results
}

\author{
Bob Baulch, Rosemary Botha, and Karl Pauw
}

This Report describes the initial results of modeling undertaken by IFPRI to assess the short-run impacts of the COVID-19 control measures on the Malawian economy. We also consider the short-run effects of external shocks associated with disruptions in trade, investment, and remittance flows on the Malawian economy, as well as two medium-term paths assuming either faster or slower recovery during the remainder of 2020 . This analysis has been undertaken in order to inform the policy response to the COVID-19 pandemic in Malawi and represents a first pass attempt to measure the short-term economic impacts of COVID-19 on the Malawian economic. It should be noted that, unlike NPC (2020) our estimates of the economic impact of the COVID-19 on the Malawian economy do not extend beyond 2020 and do not try to set a value on loss of life or life-years. They do, however, allow for detailed breakdown of the direct and indirect impacts of COVID-19 on different sectors and sub-sectors of the Malawian economy.

We employ a Social Accounting Matrix (SAM) multiplier model to assess the short-term impact of COVID-19 on the Malawian economy. A SAM depicts the economy as a series of interrelated systems of transactions, which capture the circular flow of income in an economy in a disaggregated way. We use the SAM developed for Malawi in 2014, which contains 63 productive activities, 65 commodities and 15 representative household groups. Results are scaled to current values using national accounts and population data.

We assess the short-term impacts of COVID-19 arising from two types of shocks to the Malawian economy:

a) External shocks affecting exports, trade, and remittances,

b) Policy measures arising from public health interventions implemented to combat the spread of COVID-19.

Expressing the external shocks and policy measures as effective demand shocks, we use a SAM multiplier model to assess the economywide impact of COVID-19 during the full implementation of these measures, and during two stylized recovery scenarios. 
Unlike many other African countries, Malawi adopted a moderate policy of social distancing to curb the spread of the virus. A full lockdown was proposed but never implemented. As shown in Figure 1, we estimate national GDP losses of 11.6 percent due to two months of social distancing and 22.3 percent under a hypothetical 21-day urban lockdown. This equates to GDP losses of approximately US\$ 26 million and US\$ 49 million per week, respectively, during the periods these restrictions are enforced. Between 1.1 and 2.2 million people fall temporarily into poverty under the two scenarios. Two recovery paths, involving the faster and slower easing of restrictions during the remainder of 2020 are then modelled. These suggest that Malawi's GDP would decline by 4 to 5.2 percent in 2020 under the social distancing scenario and by 6.2 to 9.1 percent had Malawi introduced the proposed 21-day lockdown.

Figure 1: Headline economic impacts of social distancing versus urban lockdown

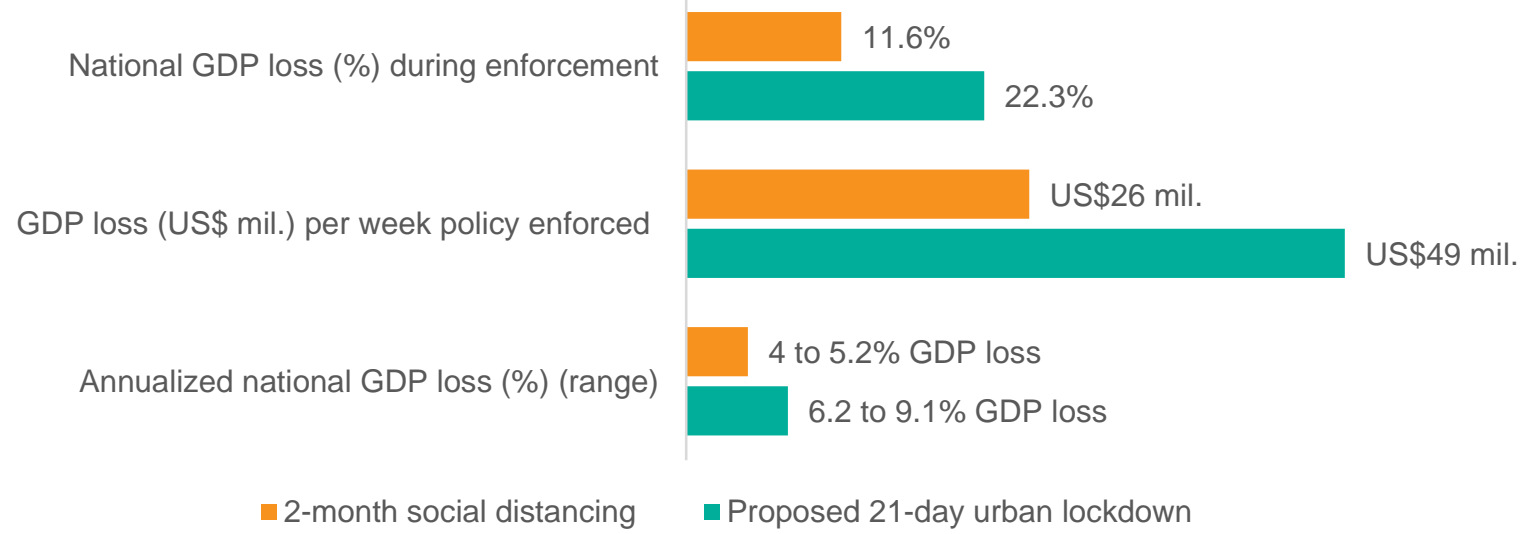

Source: Malawi SAM multiplier results.

\section{Malawi's Response to COVID-19}

According to the WHO, Malawi was one of last countries in Africa to be hit by the pandemic, not registering its first three cases until April 2, 2020. The detection of these cases post-dated the State of Disaster declared by the President on March 20, which closed all schools and universities, banned meetings with more than 100 people, and instituted social distancing measures for religious gatherings. Later in March, social distancing measures for markets and public transport were declared, the opening of the tobacco auctions was delayed, and all commercial flights were suspended from midnight on April 1. Other measures included the reduction of the liquidity reserve ratio for banks, fuel taxes and waiving the non-tourist levy to support the tourism industry. The Malawi Revenue Authority was also instructed to open up a voluntary tax compliance window for a period of six months to allow taxpayers with arrears to settle their tax obligations at a later date. All offices were advised to work in shifts except those working in essential services, and the Malawi Prison Services released some 1,400 prisoners who had committed "petty offences" to decongest the country's prisons. On April 20, non-essential Government staff were instructed to work from home.

A national COVID-19 Preparedness and Response Plan with a budget of US\$212 million was launched on April 8, with the International Monetary Fund (IMF) approving debt service relief of US\$ 9.8 million for Malawi on April 13, and the World Bank approving a US\$ 37 million package of COVID-related support on April 15. On June 4, the budget for the Plan was increased to US\$345 million, of which around three-quarters remain unfunded.

On April 14, the President announced a 21-day lockdown starting at midnight on April 18. However, on April 17, the Malawi High Court granted an injunction, which temporarily barred the Government 
from implementing the 21-day lockdown following a petition by the Human Rights Defenders Coalition, who had argued that more consultation was needed to prevent harm to the poorest and most vulnerable of society. At the time of writing (mid-June), the injunction against the lockdown is still in force.

In our SAM multiplier modeling exercise, we have therefore focused on modeling the short-term economic impacts of the moderate social distancing measures that Malawi has adopted since late March 2020. We do, however, also consider a hypothetical lockdown scenario in urban areas similar to that declared in mid-April but not, as yet, implemented because of the High Court injunction.

As of June 21, 2020, Malawi has registered a total of 749 confirmed COVID-19 cases, with 11 deaths and 258 recoveries (https://covid19.health.gov.mw/).

\section{Methodology}

Social Accounting Matrix (SAM) multiplier models are well suited to measuring short-term direct and indirect impacts of unanticipated, rapid-onset demand and supply-side economic shocks, such as those caused by the COVID-19 pandemic. At the heart of the multiplier model is a SAM, an economywide database that captures resource flows associated with all economic transactions that take place in the economy, usually over the course of a financial year. The SAM represents the structure of the economy at a point in time, showing the relationships between actors, i.e., productive activities, households, government, and foreign institutions, in terms of how they interact and transact via commodity and factor markets. The SAM multiplier model provides a mechanism for estimating the effects of an external shock - typically an exogenous change in final demand for goods and services - on sectoral and national production, factor incomes, and household incomes on the basis of the production, employment, and consumption relationships captured in the SAM database.

In addition to direct production effects in a sector affected by the demand change, other sectors are affected indirectly via changes in demand for intermediate inputs defined by input-output relationships in the SAM. Additionally, resulting changes in the levels or composition of employment could lead to further changes in household consumption demand. By capturing inter-industry and employment linkages, the model measures both the direct and indirect production and employment effects associated with demand shocks. The effects result in changes in household income, which are used to estimate changes in poverty with the aid of a microsimulation model linked to the multiplier model. The strength of the multiplier model lies in the fact that the multiple rounds of these indirect effects are fully estimated. The more detailed the SAM is in terms of the activities, commodities, factor, and household accounts it includes, the more refined the SAM multiplier analysis of the direct and indirect impact pathways and distributional effects of shocks will be.

We employ a SAM developed by the International Food Policy Research Institute (IFPRI) drawing on the National Accounts and the third Integrated Household Survey. The 2014 SAM for Malawi consists of 63 productive activities and 65 commodities, including goods and services (Thurlow 2017). The agriculture sector is disaggregated into 24 activities - 17 crop activities, 5 livestock activities, plus fishing, and forestry. The industry sector is disaggregated into 24 sub-sectors, and the services sector into 11 sub-sectors. A distinction is made in the model between rural and urban labor and, within these between several levels of skill, defined according to educational attainment. Rural and urban households are also disaggregated by their per capita consumption into quintiles, with a further distinction being made between rural farm and rural non-farm households. While the SAM itself has a 2014 base-year, our multiplier results are scaled to more recent national accounts and population aggregates (i.e., for 2018 or 2019 depending on data availability) to permit an assessment of the likely impacts of COVID-19 in 2020. 
The short-run analysis period assumes that technical input-output relationships, the output choices of producers, and the consumption patterns of households do not change in response to the simulated shocks. Such behavioral responses are captured in computable general equilibrium models. However, the anticipated short-term nature of the COVID-19 shock and the likelihood that the economy will return to "business-as-usual" state once the crisis dissipates makes the SAM multiplier framework a more appropriate tool for analyzing one-off unanticipated shocks. For further discussion of SAMs and SAM multiplier models, see Breisinger et al. (2009) and Round (2003).

\section{Economic Scenarios}

We consider two broad economic scenarios: (a) two months of social distancing applied in both rural and urban areas during April and May; and (b) a 21-day urban lockdown in the second half of April and early May combined with social distancing measures during the first half of April, and rest of May. The social distancing measures are based on the guidelines announced by the Ministry of Health in early April 2020, while the 21-day lockdown is based on the lockdown measures that were declared on April 14 but not enforced due to an injunction from the High Court. In addition to the shocks to the domestic sector, external trade shocks (reduced tobacco export revenues, and declining foreign remittances and foreign direct investment) arising from the effects of COVID-19 in the rest of the world are included. The magnitude of initial shocks applied are shown in Table 1.

Table 1: Impact channels and effective demand shocks applied during Q2, 2020

\begin{tabular}{|c|c|c|c|}
\hline \multirow[b]{2}{*}{ Impact channels } & \multicolumn{3}{|c|}{ Initial shocks during Q2 } \\
\hline & $\begin{array}{l}\text { Social distancing } \\
\text { (2 months) }\end{array}$ & $\begin{array}{c}\text { Urban lockdown } \\
\text { (21 days) }\end{array}$ & $\begin{array}{c}\text { External } \\
\text { shocks (Q2) }\end{array}$ \\
\hline Restricting non-food manufacturing operations & & $-30 \%$ & \\
\hline Restricting non-essential wholesale/retail trade & $-15 \%$ & $-50 \%$ & \\
\hline Transport and passenger travel restrictions & $-25 \%$ & $-80 \%$ & \\
\hline Limiting hotel and restaurant operations & $-80 \%$ & $-80 \%$ & \\
\hline Non-essential business services restricted & & $-30 \%$ & \\
\hline Restrictions on other business services & & $-50 \%$ & \\
\hline Government work-from-home orders & $-30 \%$ & $-30 \%$ & \\
\hline Closing all schools in the country & $-20 \%$ & $-20 \%$ & \\
\hline Banning sports \& other entertainment & & $-50 \%$ & \\
\hline Reduced tobacco exports & & & $-10 \%$ \\
\hline Falling foreign private remittances & & & $-50 \%$ \\
\hline Falling foreign direct investments & & & $-30 \%$ \\
\hline
\end{tabular}

Source: Author's construction.

The main sectors affected in the social distancing scenario are hotels and restaurant operations, which with the exception of take away food services were mostly closed during April and May, followed by work from home orders for all non-essential Government employees, and restrictions on freight and passenger transport (including the ban on all international flights from April 1). The closure of all schools, colleges and universities in the country from March 19 is also envisaged to have reduced demand by 20 percent despite the fact that teachers have continued to receive basic salaries, principally because of non-payment of school contributions and secondary school fees. Restrictions on wholesale and retailing, which to date have been less thoroughly enforced, have a smaller impact in the social distancing scenario but are ramped up along with transport during the 21-day lockdown scenario. Shocks on non-food manufacturing enterprises, businesses services 
and sports/entertainment are also envisaged during the 21-day lockdown scenario. However, agriculture, construction, health, and essential services are exempt from restrictions under both the social distancing and lockdown scenarios.

After modeling the short-term impact of these policies during their enforcement (two months for social distancing and 21 days for the lockdown), a faster and a slower easing of these restrictions are specified during the remainder of 2020 .

\section{Short-term Economic Impacts Due to Social Distancing}

Our first scenario considers two-months of social distancing and corresponds roughly to what has been observed in Malawi since the beginning of April. Using the SAM multiplier model with the social distancing and external demand shocks specified in Table 1, we estimate that national GDP falls by 11.6 percent during April and May relative to what is projected in a without COVID-19 scenario. This is equivalent to losses of approximately US\$26 million per week. Assuming linearity in the effects of the shock over time, every week social distancing measures are extended beyond the simulated two-month period, total economic losses will increase by that same amount.

Figure 2 shows the breakdown of total GDP losses by sector on the left, and the share of GDP losses accounted for by different impact channel on the right. The industry sector is hit hardest, with its value added falling by 15.2 percent followed closely by services (-14.8 percent). However, because of the relative sizes of two sectors, services are by far the most affected in absolute terms with losses of US\$155 million over the two-month period compared to US\$ 48 million in industry. The sub-sectors that are hardest hit by social distancing within services are hotel and restaurant operations and the wholesale retail trade, while external shocks due to falling foreign direct investment and remittances and reduced tobacco exports are also important. Closing of school and Government work at home orders also account for substantial shares of total GDP losses.

Figure 2: Sectoral effects of social distancing
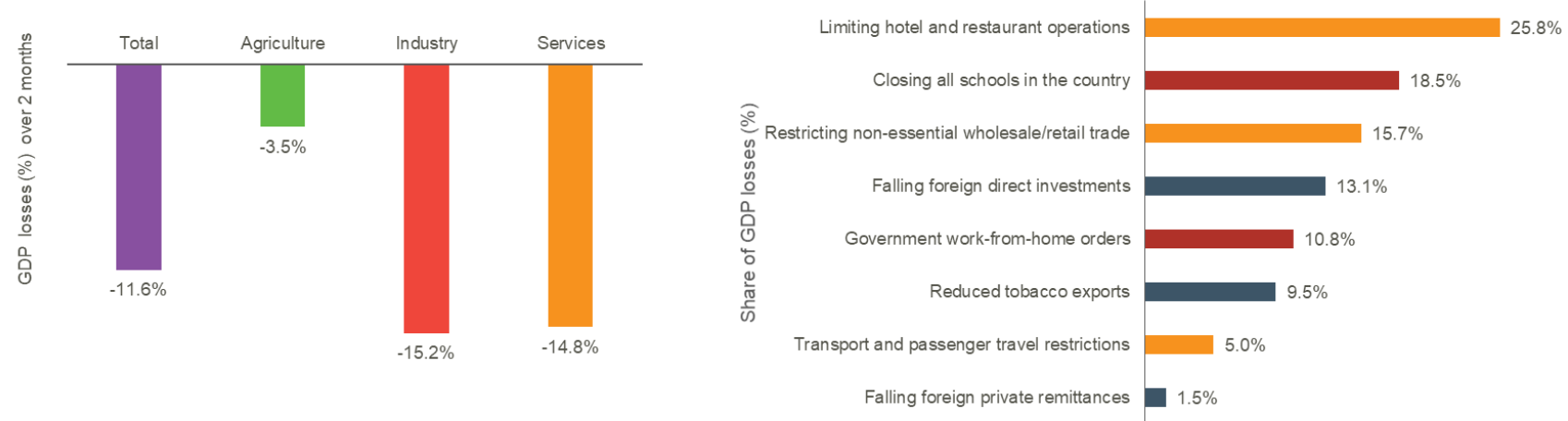

Source: Malawi SAM multiplier results.

Although the agriculture sector, which is exempt from social distancing restrictions, experiences a relatively small contraction (-3.5 percent) due to social distancing, the entire agri-food system contracts by 8.1 percent due COVID-19 related restrictions in April/May. This is due to both the direct impacts of shocks to the demand for food trade and transportation services and tobacco exports have on the agricultural sector, and the indirect impacts of shocks in other sectors on the wider agrifood system which includes agro-processing, food trade, transport and the food services. Food services, though a relatively small sector in terms of GDP, experience a decline of 73 percent due to closure of restaurants and other food outlets to all but take away services during the two months of 
social distancing. Hotel occupancy rates have also been extremely low ( $<20$ percent) due to a decline in tourist since the beginning of 2020 , and a halt in nearly all tourism since international flights were stopped at the beginning of April.

Income losses from two months of social distancing are expected across the income distribution, but with those in the richest income quintile and urban areas experiencing higher declines in their per capita incomes (Figure 3). Consequently, an additional 1.1 million poor people fall temporarily into poverty, most of whom, like the overall population, are in rural areas.

Figure 3: Changes in per capita incomes during social distancing

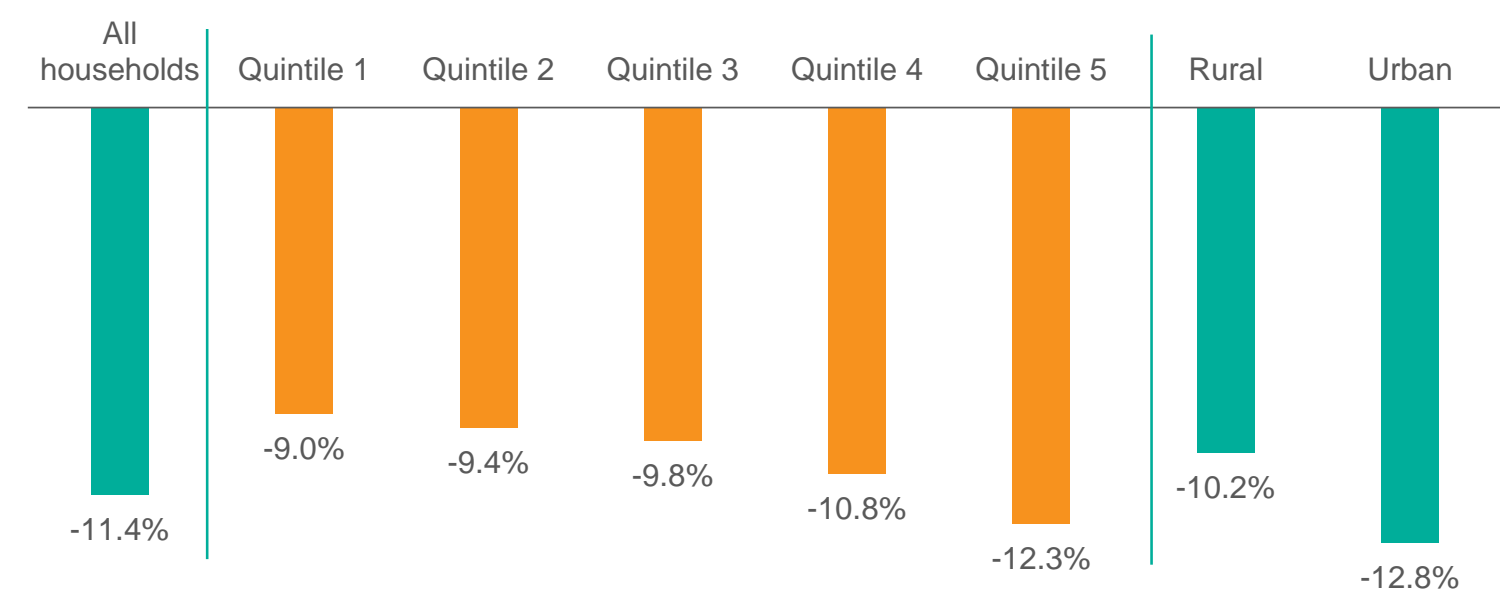

Source: Malawi SAM multiplier results.

\section{Short-term Economic Impacts due to Hypothetical 21-day Lockdown}

A 21-day lockdown was announced in Malawi in mid-April but never implemented because of a High Court injunction. Nonetheless, as lockdowns are public health measures that have been imposed in a number of other countries in the region, including South Africa and Zimbabwe, we proceed to estimate what the combined impact of a 21-day lockdown during late April/early May combined with social distancing measures during the remainder of April and May plus similar external shocks to the social distancing case would be. We restrict the lockdown to urban areas only, as we consider it would not be possible for a lockdown to be enforced in rural areas.

As can be seen in Figure 4, a 21-day lockdown in urban areas is projected to result in a 22.3 percent decline in GDP during its period of enforcement, which equates to monetary losses of US\$49 million per week, some US\$23 million/week higher than the social distancing scenario. Now it is services that experiences the greatest losses in both absolute and relative terms, with the wholesale/retail trade, hotels and restaurants and non-essential business manufacturing being the hardest hit sub-sectors. Industrial production also declines by almost a quarter ( 24.5 percent) with restrictions on non-food manufacturing having the largest impacts. 

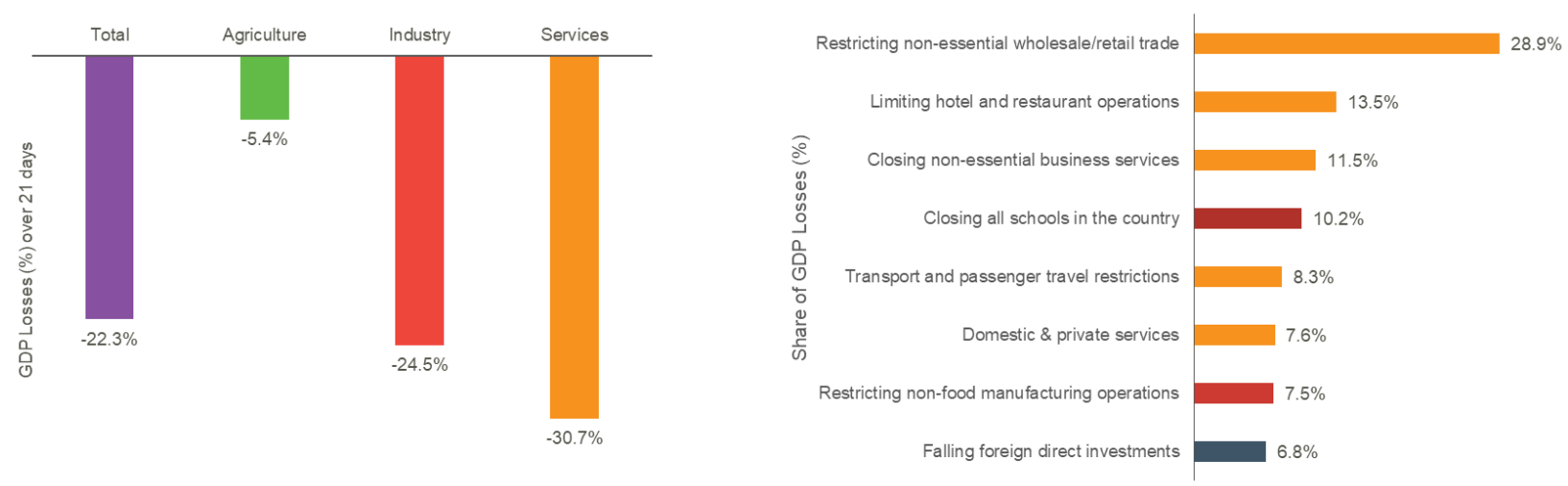

Source: Malawi SAM multiplier results.

The agriculture sector, which is exempt from lockdown restrictions, only declines by 5.4 percent during the 21-day lockdown, although direct and indirect impacts from other sectors mean that the wider agri-food system declines by 11.2 percent due to contractions in the food trade, food services and agro-processing.

A 21-day urban lockdown would increase the national poverty headcount in the short term by 2.2 million people, 1.8 million of whom are in rural areas with the remainder in urban areas. The larger increase in rural than urban poverty is also observed in the social distancing scenario and is driven by the shocks associated with school and restaurant closures, and the intensification of transport restrictions together with the proximity of many rural households to the national poverty line. Nonetheless, it is households living in urban areas and the richest quintile who experience the sharpest declines in their per capita incomes under the urban lockdown scenario. These income declines led to an 11.8 percentage point increase in the national poverty rate.

\section{Medium-Term Economic Impacts during 2020 under Two Recovery Scenarios}

Following two months of social distancing, we model the impact of a faster and a slower lifting of restrictions and external shocks during the remainder of 2020, so that by December 2020 most restrictions and shocks have disappeared. Table 2 describes the way the domestic restrictions and external shocks are relaxed in June 2020, quarters 3 and 4.

Table 2: Easing of domestic restrictions and external shocks under fast and slow recovery scenarios

\begin{tabular}{lccc} 
Period & \multicolumn{1}{c}{$\begin{array}{c}\text { Faster Easing } \\
\text { of Restrictions }\end{array}$} & $\begin{array}{c}\text { Slower Easing } \\
\text { of Restrictions }\end{array}$ & External Shocks \\
\hline June & $\begin{array}{c}70-90 \% \text { of initial domestic } \\
\text { shocks }\end{array}$ & $\begin{array}{c}95-100 \% \text { of initial domestic } \\
\text { shocks }\end{array}$ & No change \\
Quarter 3 & $\begin{array}{c}10-30 \% \text { of initial domestic } \\
\text { shocks }\end{array}$ & $\begin{array}{c}50-70 \% \text { of initial domestic } \\
\text { shocks }\end{array}$ & $50 \%$ of quarter 2 levels \\
Quarter $\mathbf{4}$ & $1-5 \%$ if initial domestic shocks & $10-20 \%$ of initial domestic \\
shocks & $25 \%$ of quarter 2 levels \\
\hline
\end{tabular}

Source: Authors' compilation.

Figure 5 shows cumulative GDP gains (in constant US\$ millions) by quarter over the course of 2020 , along with the corresponding annualized growth rates on the right-hand side. The upper teal line shows the 5.1 percent projected growth path for 2020 (MFEP\&D 2019), which translates into a 
quarterly gain of just over US\$25 million or US\$102.9 million over the year. As with our earlier simulations, COVID-19 is projected to have no impact of the Malawian economy during quarter 1 of 2020 , but to have an almost identical negative impact during quarter 2, when real GDP declines by around US\$34.5 million due to the combined impact of two months of social distancing combined with trade shocks. Thereafter, the growth paths for the rapid and slow recovery scenarios diverge with cumulative GDP losses of US $\$-1.7$ and -20.6 million respectively by the end of quarter 3 . With continued easing of restrictions in quarter 4, cumulative GDP gains turn positive by the end of the year under the fast recovery scenario, with real GDP gains of US\$17.2 million. However, under the slow recovery scenario, although GDP increases during quarters 1 and 4 , this is not sufficient to wipe out the losses in quarters 2 and 3, resulting in a net loss of US\$ 6.6 million over the entire year. Relative to the without COVID-19 scenario, US $\$ 85.7$ million of GDP is lost under the fast recovery scenario and US\$109.5 million under the slow recovery one.

Figure 5: GDP growth per quarter during 2020 with rapid and slow recovery from social distancing

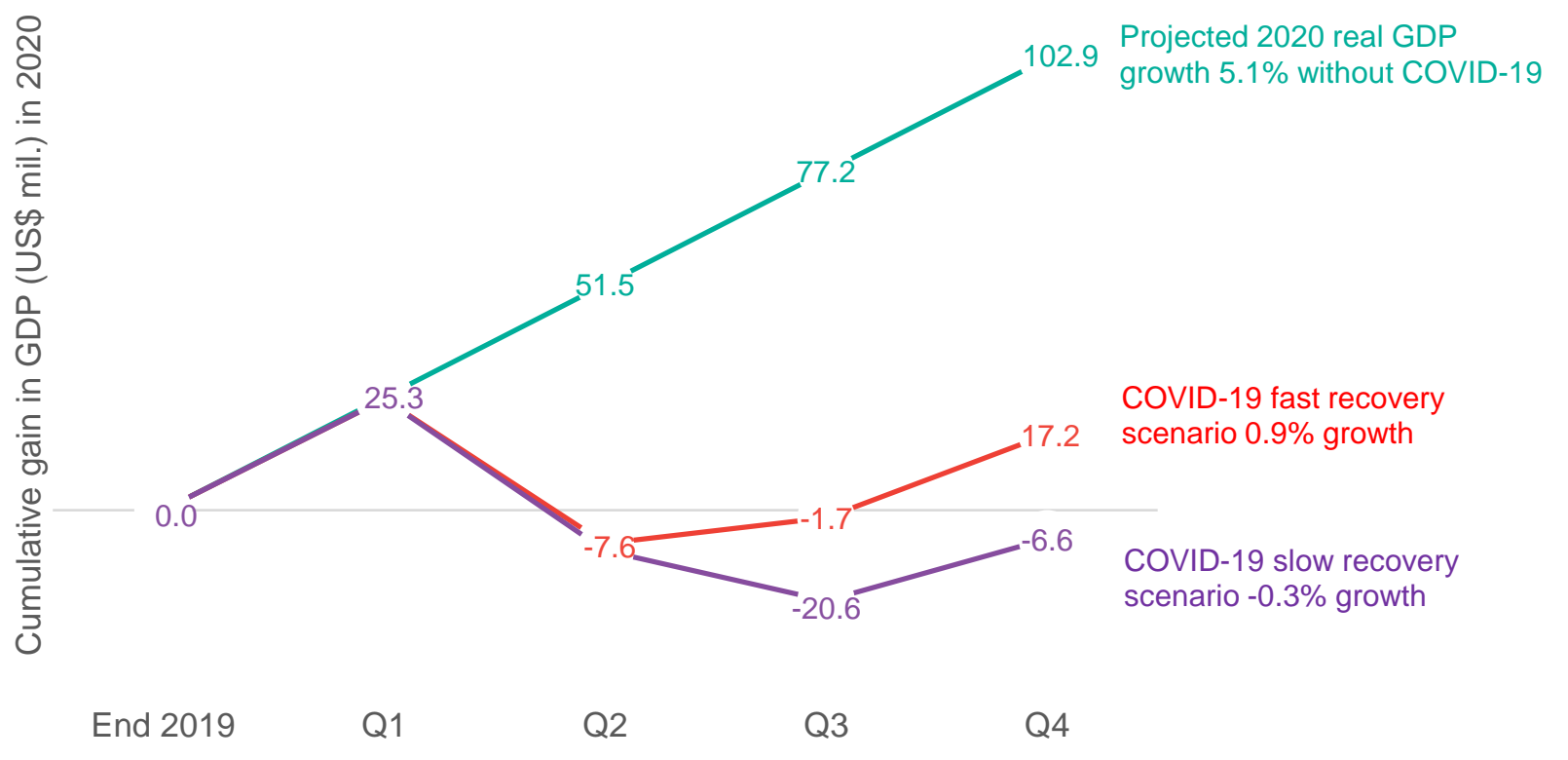

Source: Malawi SAM multiplier results.

Under these two recovery scenarios by the end of 2020, the national poverty headcount returns to 0.6 (fast recovery) to 1.0 (slow recovery) percentage points above the non-COVID scenario. This equates to between 100,000 and 190,000 thousand additional poor people.

\section{Comparison of Modeling Results with those in Other African Countries}

IFPRI has also undertaken similar -though not identical- SAM multiplier modeling in other African countries (Table 3). Such cross-country comparisons should be made cautiously due to differences in: (a) the restrictions implemented and their enforcement; (b) the demand shocks assumed; and, (c) the impact channels simulated. Nonetheless, Table 3 shows that the estimated GDP losses during the implementation of lockdowns in Ghana, Nigeria, and South Africa are considerably higher than the losses during social distancing in Ethiopia and Malawi. Furthermore, the economic losses of lockdowns are sustained through the remainder of 2020 under both faster and slower easing of restrictions. The lower short-term economic costs of more relaxed restrictions to counter COVID-19 
must clearly be balanced against their public health costs and benefits in terms of reduced infections and 'flattening of the curve'. In addition, it is still too early to know if subsequent spikes in infections may result in lockdowns or other restrictions being implemented later in the year, especially in countries which adopted more relaxed restrictions. However, as events unfold, the SAM multiplier modeling framework used here is able to be updated relatively quickly, and can be used to provide simulations of the short-term economic impacts of COVID-19 to assist in the formulation of COVID19 control and recovery measures.

Table 3: Simulated impacts of lockdowns/restrictions in selected African countries

\begin{tabular}{lcccc} 
Country & Scenario & $\begin{array}{c}\text { GDP loss } \\
\text { during } \\
\text { lockdown }\end{array}$ & $\begin{array}{c}\text { Annual GDP effects in 2020 } \\
\text { Faster easing }\end{array}$ & $\begin{array}{c}\text { Slower easing } \\
\text { Ethiopia }\end{array}$ \\
Ghana & 7-week restriction period & $-14.3 \%$ & $-4.8 \%$ & $-6.2 \%$ \\
Malawi & 2-month social distancing & $-27.9 \%$ & $-8.6 \%$ & $-12.3 \%$ \\
Nigeria & 5-8-week lockdowns staggered across various states & $-37.6 \%$ & $-4.0 \%$ & $-5.2 \%$ \\
South Africa & 3-week national lockdown & -29 to $-34 \%$ & $-5.9 \%$ & $-17.1 \%$ \\
\hline
\end{tabular}

Source: Authors' compilation from IFPRI (https://www.ifpri.org/covid-19), accessed June 9, 2020.

\section{Summary and Conclusions}

To date, Malawi's response to the COVID-19 pandemic has been relatively modest with social distancing measures adopted along with travel restrictions. Using a SAM multiplier model, we estimate GDP declines by around 11.6 percent during April/May and between 4 and 5.2 percent over the 2020 calendar year. This leads to around 1.1 million people, the majority in rural areas, temporarily falling into poverty, although it is urban households who suffer the largest income losses. These economic losses are not as heavy as the impacts simulated for a 21-day urban lockdown, which results in a 22.3 percent decline in GDP during the lockdown, a 6 to 9.1 percent decline in annual GDP, with around 2.2 million people falling temporarily into poverty. They are also less than the GDP declines simulated using similar models in other countries, such as Ghana and South Africa, that have implemented hard lockdowns.

Of course, the economic costs of COVID-19 restrictions must be set against their public health benefits and we do not yet know if the social distancing measures that Malawi has adopted have been as effective in 'flattening the curve' of infection as the harder lockdown measures imposed in other countries. Nonetheless minimizing the economic impact of COVID-19 requires: a) maintaining open markets and borders with appropriate hygiene/social distancing measures; b) social protection measures to protect the most vulnerable, especially informal services and small retailers in urban areas; and c) re-opening schools once it is safe to do so. Looking forward, monitoring the impact of COVID-19 restrictions on the Malawian economy should pay special attention to the urban informal service sector, the wider agri-food system, hotels and restaurants, as well as tourism, exports, and remittances-as these are the sectors that our analysis shows to be most impacted by COVID-19 restrictions in Malawi. 


\section{ABOUT THE AUTHORS}

Bob Baulch is a Senior Research Fellow in the Development Strategy and Governance Division (DSGD) of IFPRI and Country Program Leader of the Malawi Strategy Support Program (MaSSP).

Rosemary Botha is a Research Analyst with IFPRI Malawi.

Karl Pauw is a Senior Research Fellow in the Development Strategy and Governance Division (DSGD) of IFPRI and Program Leader of the Ghana Strategy Support Program (GSSP).

\section{ACKNOWLEDGMENTS}

Funding for this report was kindly provided by the CGIAR Program on Policy, Institutions, and Markets (PIM), the UK Department for International Development (DFID), and the United States Agency for International Development (USAID). The authors thank James Thurlow, Jan Duchoslav and webinar participants for helpful comments on earlier versions of this study, and Sandra Fröbe for editorial support.

This publication has not been peer reviewed. Any opinions stated in this publication are those of the authors and are not necessarily representative of or endorsed by IFPRI.

\section{REFERENCES}

Breisinger, C., M. Thomas, and J. Thurlow. 2009. Social Accounting Matrices and Multiplier Analysis: An Introduction with Exercises Food Security in Practice Technical Guide 5. Washington, DC: International Food Policy Research Institute. http://dx.doi.org/10.2499/9780896297838fsp5

MFEP\&D (Ministry of Finance, Economic Planning and Development). 2019. Annual Economic Report. Lilongwe: Ministry of Finance, Economic Planning and Development.

NPC (National Planning Commission). 2020. Medium and long-term impacts of a moderate lockdown (social restrictions) in response to the COVID-19 pandemic in Malawi: A rapid cost-benefit analysis. National Planning Commission with technical support from the Copenhagen Consensus Center and the African Institute for Development Policy.

Round, J. 2003. "Social Accounting Matrices and SAM-based Multiplier Analysis." In Techniques and Tools for Evaluating the Poverty Impact of Economic Policies, edited by F. Bourguignon and L. A. Pereira da Silva, Chapter 14. Washington, DC and Oxford, UK: World Bank and Oxford University Press.

Thurlow, J. 2017. 2014 Social Accounting Matrix for Malawi: A Nexus Project SAM. Washington DC: International Food Policy Research Institute.

\footnotetext{
The Malawi Strategy Support Program (MaSSP) is managed by the International Food Policy Research Institute (IFPRI) and is made financially possible by the generous support of the American people through the United States Agency for International Development (USAID), and by the UK Department for International Development (DFID). This publication has been prepared as an output of MaSSP and has not been independently peer reviewed. Any opinions expressed here belong to the authors and are not necessarily representative of or endorsed by IFPRI, the US or the UK government's official policies, or CGIAR.
}

\section{INTERNATIONAL FOOD POLICY RESEARCH INSTITUTE A world free of hunger and malnutrition

